\title{
Inhibition of Prostatic Epithelial Cell Proliferation by a Factor Secreted Specifically by Prostatic Stromal Cells
}

\author{
Anko Kooistra, Josée J. König, Diederick M. Keizer, Johan C. Romijn, and \\ Fritz H. Schröder \\ Department of Urology, Erasmus University/Academic Hospital Rotterdam, Rotterdam, \\ The Netherlands
}

\begin{abstract}
Stromal cells from the prostate were recently shown to inhibit clonal growth of the prostatic carcinoma cell lines PC-3 (hormone-independent) and LNCaP (hormone-sensitive) in coculture. Our study revealed that stromal cell-conditioned medium strongly inhibited proliferation of PC-3 and LNCaP cells when grown in monolayer culture. Antiproliferative activity was found to be reversible, and was produced specifically by prostatic stromal cells and not by stromal cells derived from skin, foreskin, uterus, kidney, and Wilms' tumor. Inhibition was not species-specific, since the cell lines AT-2.1 and MATLyLu, derived from the Dunning rat prostate tumor, were also sensitive. No inhibition, however, occurred on breast and renal carcinoma cell lines, suggesting a prostate-specific action. The putative inhibiting factor(s) could be concentrated and partially purified by ammonium sulfate precipitation. The possible role in stromal control of epithelial cell proliferation is discussed. (C) 1995 Wiley-Liss, Inc.
\end{abstract}

KEY WORDS: stromal-epithelial interactions, growth inhibitor, prostatic cancer, benign prostatic hyperplasia, transforming growth factor $\beta$

\section{INTRODUCTION}

Since the observation was made that the epithelium loses its growth capacity when separated from the stroma [1], it has become increasingly clear that stromal-epithelial interactions play an important role in the local control of prostatic growth. The importance of embryonic mesenchyme in prostatic ductal morphogenesis, and epithelial cell growth and differentiation, has been demonstrated by a unique series of tissue-recombinant experiments [2]. Several observations have indicated that these interactions might have retained their integral role in the adult prostate as well $[2,3]$. It is for this reason that the development of cancer and other disease states is thought to involve a loss of coordination in such interactions. McNeal [4] has already suggested the reversion of prostatic stroma to an "embryological state," inducing inappropriate epithelial proliferation in benign prostatic hyperplasia (BPH).

Upon maturation, accessory sexual organs reach a typical size and weight which is characteristic for those particular organs [2]. Likewise, administration of testosterone to androgen-deprived rats restores the size of the prostate to its normal precastration level without inducing overgrowth, even after prolonged administration [2]. At that stage, epithelial cell proliferation is low and in balance with cell death [5]. Experiments performed by Cunha and Chung [6] showed that epithelial cell growth and, therefore, absolute prostatic size was regulated by the amount of mesenchymal (stromal) tissue present. During embryological development, androgen receptors are present only in the mesenchyme, indicating that all androgen-induced events are mediated via the stroma $[2,3]$. Furthermore, it was also shown that in

Received for publication July 26, 1993; accepted May 20, 1994.

Address reprint requests to Anko Kooistra, Department of Urology, Erasmus University/Academic Hospital Rotterdam, P.O. Box 1738, 3000 DR Rotterdam, The Netherlands. 
the adult rat prostate, the proliferative response to androgens was mediated through the stroma [7]. At this point it is tempting to speculate upon a similar role of the stroma in castration-induced involution of the gland. Androgen-induced stromally derived inhibitors of epithelial cell growth would participate in keeping the delicate balance between cell proliferation and programmed cell death. The observation that rat and human prostatic epithelial cells grown in vitro are able to proliferate in serum-free medium without the presence of androgens [8-11], while androgen ablation in vivo induces a marked regression of the glandular epithelium [5], indicates a major role for the stroma in a negative control of epithelial cell proliferation. Several investigators have been searching for the molecular basis of this homeostatic constraint mechanism that curtails further increase in cell number once the gland has reached its predetermined size. Biochemical analyses have shown the presence of (polypeptide) growth inhibitors in the prostate but, since these determinations were performed on whole-tissue homogenates, it is still not clear whether these are produced by the stroma or the epithelium $[12,13]$.

The present study further explores the hypothesis of a negative control by the stroma. Using a two-layer soft agar assay, we previously observed an inhibition of the clonal growth of human prostate tumor epithelial cell lines PC-3 (hormone-independent) and LN$\mathrm{CaP}$ (hormone-sensitive) by cocultured prostatic stromal cells [14]. To elucidate this interaction further, we established a number of stromal cell cultures from human prostatic carcinomas as well as benign prostatic hyperplasia nodules, and investigated the influence of conditioned medium (CM) of these cultures on the anchorage-dependent growth (monolayer cultures) of different epithelial cell lines from human and murine origin. Likewise, several nonprostatic stromal cell cultures were initiated, and their CM tested. The results demonstrated that only prostatic stromal cells accumulate inhibitory activity in the (conditioned) medium. Anchorage-dependent as well as anchorage-independent growth of prostatic carcinoma cell lines was inhibited in a dose-related fashion. The possible role of the stroma in a negative control of epithelial cell proliferation is discussed.

\section{MATERIALS AND METHODS}

\section{Stromal Cell Cultures}

Histologically proven tissue specimens from benign prostatic hyperplasia $(\mathrm{BPH})$ and prostatic carcinoma (PC), obtained by surgery, were cut into pieces (approximately $1 \times 2 \mathrm{~mm}$ ) and placed in $35 \mathrm{~mm}$ petri dishes (Nunc) containing $1.5 \mathrm{ml}$ basal medium:
Earle's Minimum Essential Medium (Gibco Europe, Breda, the Netherlands) supplemented with $10 \%$ Fetal Calf Serum (FCS) (Biological Industries, Beth Haemak, Israel), $2 \mathrm{mM}$ glutamine, penicillin, and streptomycin (all from Gibco Europe). Cultures were maintained in a humidified incubator at $37^{\circ} \mathrm{C}$ in $5 \%$ $\mathrm{CO}_{2} /$ air. Medium was replaced twice a week. The initial halo of epithelial cells grown from these explant cultures became overgrown with fibroblast-like cells within several weeks. Subsequently, cells were detached by trypsinization $(0.05 \%$ in 0.02 EDTA) (Gibco Europe) and split in a 1:3 ratio every 2-3 weeks. In order to minimize the number of epithelial cells in our cultures (none were detected morphologically), we only used prostatic stromal cells of passage numbers 4-9 in this study. Using the monoclonal antibody NCL5D3 (Organon, Oss, The Netherlands) reacting with Keratins 8, 18, and 19, we found the number of positive cells in these cultures (BPH as well as PC) varying between $0-5 \%$, indicating that nearly all cells were of nonepithelial origin. Stromal cell cultures from skin, foreskin, uterus, kidney, and Wilms' tumor specimen were established in the same way.

\section{Cell Lines}

The prostatic carcinoma cell line PC-3, obtained from Flow Laboratories (Irvine, Scotland) and maintained in basal medium, was used between passage numbers 30-45. LNCaP-FGC cells (used at passage numbers $65-70$ ), originally made available to us by Dr. J. Horoszewicz (Buffalo, NY), and the Dunning rat prostate tumor cell lines AT-2.1 and MATLyLu, kindly provided by Dr. J.A. Schalken (University of Nijmegen, The Netherlands), were all cultured in RPMI 1640 (Gibco Europe) supplemented with 10\% FCS, glutamine, and antibiotics. The renal carcinoma cell line RC-21, established at our laboratory, was cultured in basal medium. The breast carcinoma cell line MCF-7 (pass. nr. 330), generously given by Dr. P.M.J.J. Berns (Daniël den Hoed Cancer Center, Rotterdam, The Netherlands), was cultured in RPMI 1640 (Gibco Europe) containing 10\% FCS, $2 \mu \mathrm{g} / \mathrm{ml}$ insulin (Sigma, St. Louis, MO), glutamine, and antibiotics. All cultures were shown to be free of mycoplasma contamination by staining with Bisbenzimide (Hoechst dye 33258) obtained from Sigma.

\section{Collection of Conditioned Medium (CM)}

Prostatic stromal cell conditioned medium $(\approx 0.2$ $\mathrm{ml} / \mathrm{cm}^{2}$ ) was collected twice a week from confluent monolayers. After centrifugation $(6,000 \mathrm{~g} ; 20 \mathrm{~min}$; $\left.4^{\circ} \mathrm{C}\right), \mathrm{CM}$ was stored at $-20^{\circ} \mathrm{C}$ until further use. 


\section{Growth Inhibition Assay}

Inhibition of anchorage-dependent cell growth was determined by means of a colorimetric assay based on the reduction of a tetrazolium salt, 3-(4,5dimethylthiazol-2-yl)-2,5-diphenyl tetrazolium bromide (MTT), to a colored formazan product (maximum absorption at $560 \mathrm{~nm}$ ) by mitochondrial enzymes present only in living, metabolically active cells [15]. Results of these MTT-tests performed on prostatic epithelial cell lines were shown to correlate well with those obtained with $\left[{ }^{3} \mathrm{H}\right]$-thymidine incorporation assays and with direct DNA measurements $[15,11]$. Cells were harvested by trypsinization, resuspended in fresh culture medium, and plated in a volume of $0.1 \mathrm{ml}$ per well in 96-well microtiter plates (Costar). Inoculum: 2,000 PC-3 cells per well. The next day (day 0), $0.1 \mathrm{ml}$ of sample was added, resulting in a total volume of $0.2 \mathrm{ml}$, with a $50 \%$ dilution of the sample and a (basal) FCS concentration of $5 \%$. At day $3,30 \mu \mathrm{l}$ of a $5 \mathrm{mg} / \mathrm{ml}$ solution of MTT (Sigma) in PBS was added to each well. After a 4-hr incubation at $37^{\circ} \mathrm{C}$ in $5 \% \quad \mathrm{CO}_{2} /$ air, the medium was carefully drawn off and the purple dye was dissolved in $0.1 \mathrm{ml}$ DMSO (Merck, Darmstadt, Germany) containing $12.5 \%$ of a $0.1 \mathrm{M}$ Sörensen buffer $\mathrm{pH} 10.5$. Plates were placed on a plate shaker for $5 \mathrm{~min}$, and the absorbance at $560 \mathrm{~nm}$ was read using a Flow Titertek Multiskan plate reader. Unless otherwise stated, eight replicate wells were used for each sample. Wells containing medium but no cells served as blanks. Results are expressed as percentage of maximal growth from day 0 , obtained in fresh basal medium. To determine the number of cells at this point, one extra plate was read at day 0 .

\section{Growth Curves}

Growth curves (Fig. 1) were determined in the presence of $\mathrm{CM}$ previously dialyzed (Spectrapor 3-cutoff: 3500 Dalton; Spectrum Medical Ind., Los Angeles, CA) against basal medium without serum. In order to avoid the formation of a confluent monolayer, PC-3 cells were plated at a density of 1,000 cells/well. MTT-tests were performed on separate plates at the days indicated.

\section{Production of Inhibitory Activity}

Stromal cells were plated in 24-well plates in $0.6 \mathrm{ml}$ $\left(\approx 0.3 \mathrm{ml} / \mathrm{cm}^{2}\right)$ of basal medium and left to attach overnight. All wells were changed to fresh medium twice a week (days $1,4,8$, and 11). At the days indicated, CM was harvested from two wells, pooled, and stored at $-20^{\circ} \mathrm{C}$ after centrifugation. Subsequently, both monolayers were trypsinized and via-

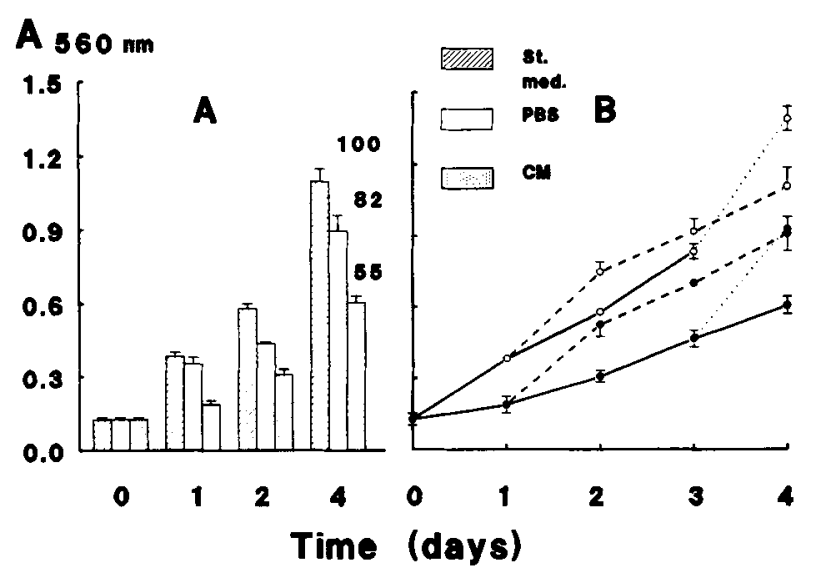

Fig. I. A: Inhibition of PC-3 cell growth by prostatic stromal cell $C M$. The left axis gives the absorbance at $560 \mathrm{~nm}$ as determined by the MTT test. Data labels on the right indicate the percentage of growth compared to proliferation in basal medium. B: Reversibility of inhibition. At day I or day 3, half of the cultures were changed to fresh basal medium. Cultures initiated with $\mathrm{CM}, \bullet$. Cultures initiated with basal medium, $O$. Continuous lines, no medium change. Dashed lines, medium change at day I. Dotted lines, medium change at day 3. Inoculum, I,000 cells/well. Error bar, SD.

ble cells counted after addition of Trypan-blue. The average of these cell counts is given. After all samples were collected, inhibition of PC-3 cell growth by the respective CM was tested by means of the MTT-assay.

\section{Concentration and Partial Purification of CM}

$\mathrm{CM}$ of different passages was pooled and fractionated by ammonium sulfate precipitation. This was performed through a stepwise increase in the level of saturation by adding solid ammonium sulfate (Sigma) to the medium at $0^{\circ} \mathrm{C}$ under continuous stirring [16]. At every $10 \%$ rise, the solution was centrifuged $\left(10,000 \mathrm{~g} ; 4^{\circ} \mathrm{C} ; 20 \mathrm{~min}\right)$ and the pellet dissolved in PBS (Gibco). During this procedure, $\mathrm{pH}$ did not drop below 6.5. Samples from supernatant and pellet were extensively dialyzed (cutoff: $3.5 \mathrm{kD}$ ) at $4^{\circ} \mathrm{C}$ against PBS and MEM, respectively, and stored at $-20^{\circ} \mathrm{C}$ after sterilization through a $0.45 \mu \mathrm{m}$ membrane (Schleicher \& Schuell, 's-Hertogenbosch, The Netherlands). Osmolarity was checked to be 275-325 mOsm, using a Roebling osmometer (Vogel, Giessen, Germany).

\section{Protein Determination}

Protein concentrations were measured with the Bio-Rad Protein Assay Kit (Bio-Rad Labs, Veenendaal, The Netherlands). A 1:1-mixture of the albumin and globulin solutions was used as a standard. 


\section{Statistical Analysis}

All statistical comparisons were made using Student's paired $t$ test analyses. Differences were considered statistically significant if the two-tailed $P$ value was smaller than 0.05 .

\section{RESULTS}

\section{Effect of Prostatic Stromal Cell CM on PC-3 Cells in Monolayer Cultures}

Anchorage-independent growth of human prostatic tumor epithelial cell line PC-3 was reported to be inversely correlated with the number of human prostatic stromal cells present in coculture experiments. Furthermore, it was shown that stromal cell CM inhibited clonal growth of the hormone-independent PC-3 cells as well as the hormone-sensitive prostatic carcinoma cell line LNCaP [14]. As depicted in Figure $1 \mathrm{~A}$, the anchorage-dependent culture (monolayer) of PC -3 cells was also inhibited by prostatic stromal cell $\mathrm{CM}$. Growth inhibition, as determined by the MTTtest, of up to $45 \%$ was observed on the fourth day, as compared to growth in basal medium. At day 1 and day 2 the proliferation in CM was 53 and $55 \%$ of the controls, respectively. Growth in phosphate-buffered saline (PBS) was better than that found in dialyzed $\mathrm{CM}$, indicating that the inhibition was not merely due to depletion of nutrients or mitogens from the medium, but was caused by diffusible growth inhibiting factor(s) present in the CM. Replacing CM with basal medium after 1 day of incubation resulted in a growth rate similar to that of controls (Fig. 1B). At that time, $\mathrm{CM}$ had decreased cell number to $50 \%$ of the control. However, no "catch-up" growth was observed. Similar observations were made when media were changed at day 3 . These findings indicate that inhibition was reversible after removal of the inhibitory stimulus.

\section{Production of Inhibitory Activity by Prostatic Stromal Cells}

Figure 2, illustrating the "kinetics" of production, demonstrates the positive correlation between the number of stromal cells present and the level of inhibition induced by their respective $\mathrm{CM}$. About $30,000-40,000$ cells $/ \mathrm{cm}^{2}$ were needed to induce a statistically significant inhibition (more than $15 \%$ ) of PC- 3 cell growth. This level of inhibition was reached at day 2 and day 7 , respectively, in cultures plated at high and low density. However, at higher cell densities $\left(\geq 50,000\right.$ cells $/ \mathrm{cm}^{2}$ ), the correlation between cell number and inhibition no longer existed. Both cultures became density-arrested at the end of the second week. At this point, the graph shows that inhib-

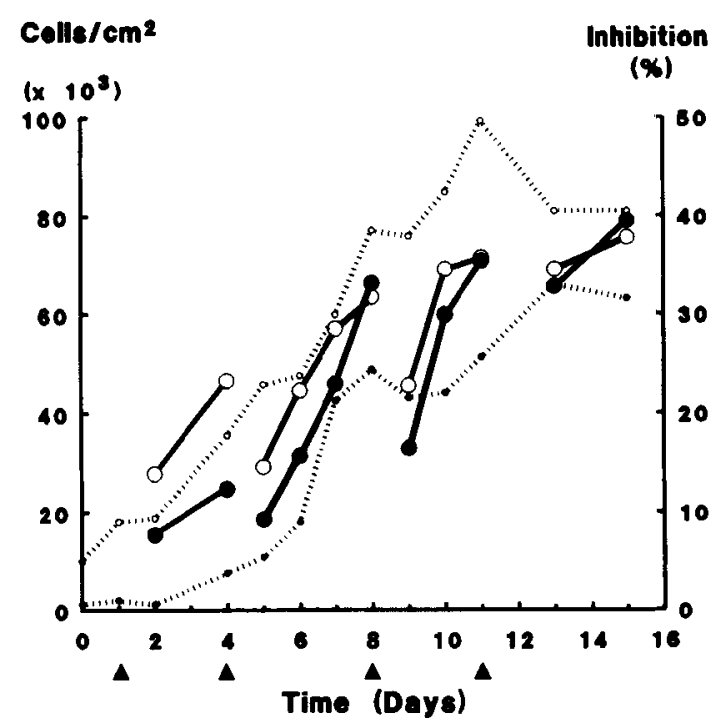

Fig. 2. Production of inhibitory activity by prostatic stromal cells. Cells were plated in 24-well plates at two densities: a) 10,000 cells $/ \mathrm{cm}^{2}$ (open symbols), and b) 1,000 cells $/ \mathrm{cm}^{2}$ (closed symbols). Medium was changed twice a week $(\boldsymbol{\Delta})$. At the days indicated, samples were taken and cell number counted (two wells). Left axis gives the number of stromal cells per $\mathrm{cm}^{2}$ represented by the dotted lines. Solid lines represent the inhibition of PC-3 cell growth by the respective $\mathrm{CM}$ as shown on the right axis. As a control, basal medium was incubated without celis, centrifugated, and stored as CM. Levels of significance were calculated using these control values. Inhibition $>15 \%$ showed to be statistically significant $(P \leq 0.05)$, while values $>20 \%$ were highly significant $(P \leq 0.005)$.

itory activity still accumulated in time, illustrating its independence of proliferation as reported earlier [14]. However, despite a clear difference in cell number, the $\mathrm{CM}$ caused equal levels of inhibition. Although the activity of the CM still appeared to be rising after four days, we considered this to be the maximal period for conditioning, for two reasons. First, after four days without medium refreshment, the stromal cells appeared less viable. Some cells detached from the substratum and were washed away with the medium, as is seen on day 8 . Second, maximal activity, present in medium covering a confluent monolayer of stromal cells, usually did not exceed the $45 \%$ level, irrespective of whether it was conditioned for four days or longer. The fact that concentrating the $\mathrm{CM}$ enabled us to obtain higher levels of inhibition (see below), indicated that this critical level was not due to limitations in our test system.

In order to find out if the passage number of the stromal cell cultures affected activity, several cultures were initiated and maintained for several months. As is depicted in Table IA, levels between $35-45 \%$ inhibition were consistently found in $\mathrm{CM}$ from nearly all 
TABLE I. Inhibition of PC-3 Cell Growth by CM From Different Stromal Cell Cultures*

\begin{tabular}{|c|c|c|c|c|c|c|c|}
\hline \multicolumn{4}{|c|}{ A. Prostate derived stromal cell cultures ${ }^{\mathrm{a}}$} & \multicolumn{4}{|c|}{ B. Nonprostatic stromal cell cultures } \\
\hline Culture & Pass nr & $\begin{array}{l}\text { Number of } \\
\mathrm{CM} \text { tested }\end{array}$ & $\begin{array}{c}\% \text { inhibition } \\
\text { (average) }\end{array}$ & Culture & Pass nr & $\begin{array}{l}\text { Number of } \\
\text { CM tested }\end{array}$ & $\begin{array}{l}\% \text { inhibition } \\
\text { (average) }\end{array}$ \\
\hline PA 517 & 5 & 11 & 40 & HF 10.3 & 9 & 9 & 8 \\
\hline \multirow[t]{4}{*}{ PA 518} & 4 & 4 & 30 & Skin & 10 & 24 & 18 \\
\hline & 6 & 9 & 40 & & 11 & 13 & 13 \\
\hline & 7 & 7 & 38 & & & & \\
\hline & 8 & 14 & 37 & FS 1 & 3 & 2 & 7 \\
\hline PA 519 & 6 & 11 & 45 & Foreskin & 4 & 6 & 14 \\
\hline \multirow[t]{4}{*}{ PA 520} & 4 & 8 & 39 & & & & \\
\hline & 5 & 13 & 40 & Ut 1 & 3 & 29 & 13 \\
\hline & 6 & 9 & 41 & Uterus & & & \\
\hline & 7 & 25 & 48 & & & & \\
\hline \multirow[t]{3}{*}{ PA 526} & 3 & 5 & 39 & WT 3 & 4 & 9 & 17 \\
\hline & 4 & 8 & 39 & Wilms' tumor & & & \\
\hline & 5 & 6 & 39 & & & & \\
\hline \multirow{2}{*}{ PA 527} & 3 & 15 & 35 & WT 7 & 5 & 7 & 9 \\
\hline & 4 & 13 & 38 & Wilms' tumor & & & \\
\hline \multirow[t]{4}{*}{ PC 239} & 4 & 5 & 36 & & & & \\
\hline & 5 & 6 & 32 & NN 1 & 3 & 3 & 16 \\
\hline & 6 & 13 & 35 & Kidney & 4 & 3 & 9 \\
\hline & 7 & 35 & 37 & & 5 & 5 & 18 \\
\hline \multirow[t]{3}{*}{ PC 242} & 3 & 3 & 40 & & & & \\
\hline & 4 & 7 & 40 & & & & \\
\hline & 5 & 37 & 43 & & & & \\
\hline \multirow[t]{2}{*}{ PC 245} & 4 & 10 & 38 & & & & \\
\hline & 5 & 10 & 42 & & & & \\
\hline PC 259 & 4 & 13 & 32 & & & & \\
\hline
\end{tabular}

*Cultures were initiated and subcultured as described in Materials and Methods. Twice a week, CM from confluent monolayers was harvested and fresh medium was given. Centrifuged $\mathrm{CM}$ was stored at $-20^{\circ} \mathrm{C}$. Within four weeks, the antiproliferative effect of these undialyzed samples was measured.

aA, benign prostatic hyperplasia; PC, prostate cancer.

stromal cell cultures derived from both malignant (PC) and nonmalignant (BPH) prostates. However, no clear-cut differences in activity were seen between $\mathrm{CM}$ of subsequent passages.

\section{Production of Inhibitory Activity by Nonprostatic Stromal Cell Cultures}

Table IB lists the growth of PC-3 cells in CM obtained from stromal cell cultures derived from skin, foreskin, normal uterus, Wilms' tumor, and normal kidney tissue. Cultures were initiated, subcultured, and CM tested in essentially the same way as prostate-derived cultures. No biologically significant inhibition of PC-3 cell growth occurred, especially if it is taken into account that 5-10\% less growth inhibition was observed when depleted nutrients were replaced by dialyzing these samples against medium (not shown). These data demonstrated that induction of inhibitory activity was confined to prostatic stromal cells, strongly suggesting an organ-specific production.

\section{Concentration and Partial Purification of CM}

In order to concentrate inhibitory activity, we performed an ammonium sulfate precipitation of CM. Figure 3 demonstrates that nearly all inhibiting activity was found in the pellet formed between $40-50 \%$ saturation. As a result, the remaining supernatant no longer had a negative effect on cell growth. These findings indicate that the inhibition was caused by precipitable factor(s) in the $\mathrm{CM}$ and was not due to depletion of nutrients or growth stimulating factors. Approximately $25 \%$ of the total amount of protein originally present in the CM was delivered in the concentrated fraction, while $75 \%$ could be discarded. Essentially the same results were obtained when the number of steps was reduced (i.e., $0-40 \%, 40-50 \%$, and $50-100 \%$ saturation). Serial dilution curves of 


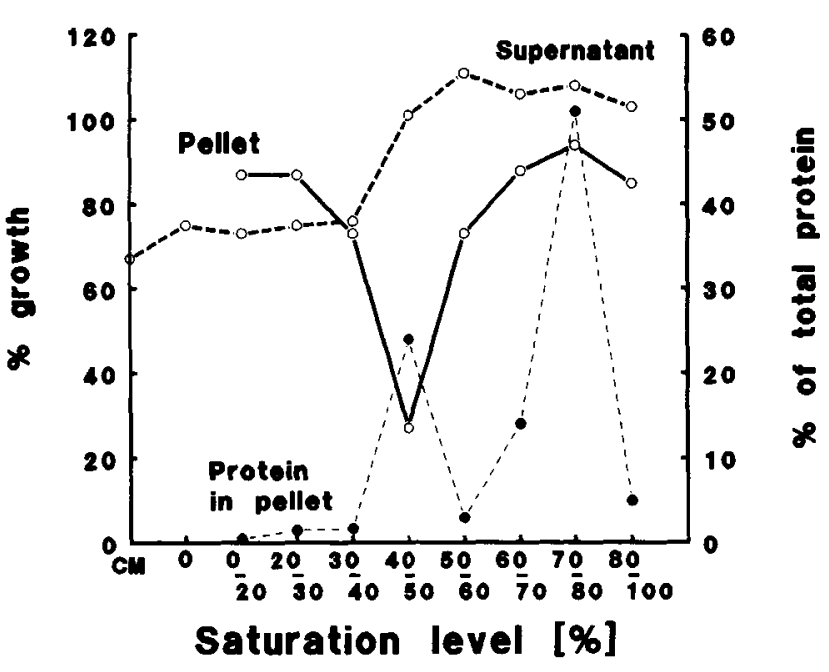

Fig. 3. Concentration of inhibitory activity by ammonium sulfate precipitation. The saturation level was increased stepwise, and the effect of pellet and remaining supernatant tested on PC-3 cell growth after dialysis (open dots and left axis). The amount of protein in the pellet is given as a percentage of the total protein present in the original solution (closed dots and right axis).

such a preparation are shown in Figure 4. Inhibition of PC-3 cell growth reached its maximum of approximately $60 \%$ compared to controls, at a protein concentration of $2 \mathrm{mg} / \mathrm{ml}$. Using other, more concentrated preparations, inhibition levels of up to $90 \%$ were found at protein concentrations of about $4 \mathrm{mg} /$ $\mathrm{ml}$. In a comparative experiment, bovine serum albumin (BSA) was shown to interfere with cell growth only at higher concentrations: approximately $10 \%$ inhibition at $6 \mathrm{mg} / \mathrm{ml}$. These findings indicate that the observed inhibition of semipurified inhibitor was not merely due to a high protein content. Basal medium and skin-derived stromal cell CM were fractionated by the same procedure in order to investigate the possibility that the observed effects were caused by concentration and/or activation of serum-derived growth inhibitors. The effect of these preparations on cell growth (tested at concentrations up to $6 \mathrm{mg} / \mathrm{ml}$ ) did not differ significantly from control cultures, again indicating that inhibition caused by prostate stromal cell CM was not due to a high protein concentration.

\section{Inhibition of Epithelial Cell Lines}

As shown in Figure 4A, different human prostatic carcinoma (epithelial) cell lines were inhibited when grown in monolayer culture. Anchorage-dependent growth of both the hormone-insensitive cell line PC-3 and the androgen-responsive cell line $\mathrm{LNCaP}$ was inhibited in a dose-related fashion. Figure $4 \mathrm{~B}$ illustrates

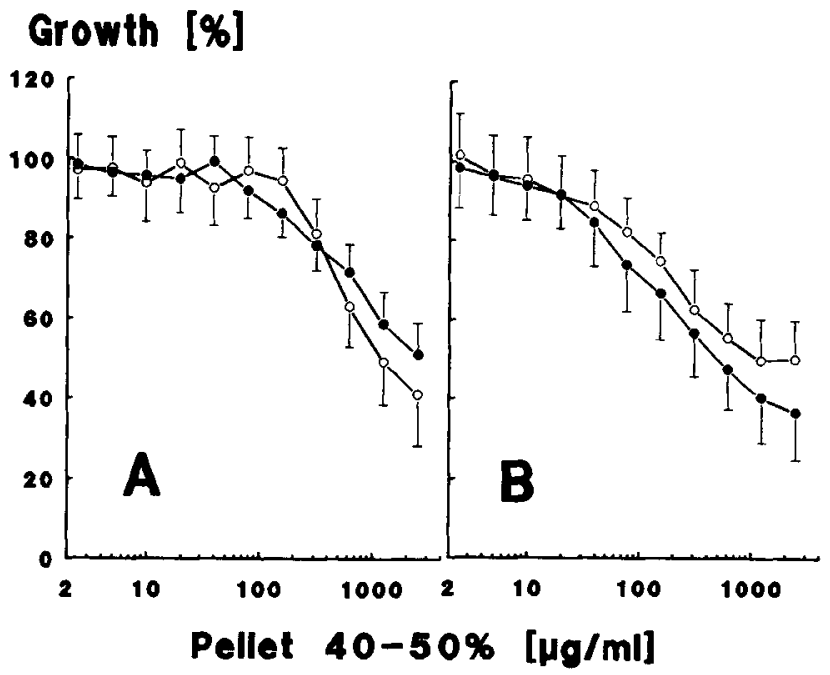

Fig. 4. Serial dilutions of concentrated CM (Pellet 40-50\%) on (A) human prostatic carcinoma cell lines PC-3 $(O)$ and LNCaP $(\bullet)$, and $(\mathbf{B})$ cell lines derived from the Dunning tumor (rat prostate) AT2.1 (O) and MATLyLu (•). Inoculum: PC-3, 2,000; LNCaP, 5,000; AT-2.I and MATLyLu, 2,000 cells/well. Bars, SD.

that similar results were obtained with epithelial cell lines AT-2.1 and MATLyLu, derived from the Dunning rat prostate tumor. These findings indicate that the growth-inhibiting factor present in $\mathrm{CM}$ did not have a species-specific effect. Preliminary tests on primary epithelial cell cultures (second passage), derived from $\mathrm{BPH}$ and prostatic carcinoma, showed these cells to be inhibited as well. Growth assays performed on the human breast carcinoma cell line MCF-7 as well as on the human renal carcinoma cell line RC-21 did not show inhibitory activity (Fig. 5). These findings suggest that $\mathrm{CM}$-derived inhibition may be prostate-specific.

\section{DISCUSSION}

Cellular proliferation in the prostate is controlled by a complex interaction of different cell types with soluble peptide growth factors, (steroid) hormones, and constituents of the extracellular matrix. It is likely that the array of peptide factors which play a role in the regulation of cell attachment and proliferation affects these processes through both positive and negative control mechanisms. Several epithelial cell growth-promoting peptides have been identified in the prostate and in prostate-derived epithelial cell cultures $[17,18]$; some of them have been positively identified as also being produced by stromal cells, suggesting a role in stromal-epithelial interactions [19-21]. Following the observation that urogenital sinus mesenchyme plays a major role in the androgeninduced development of the gland [2], stroma has 


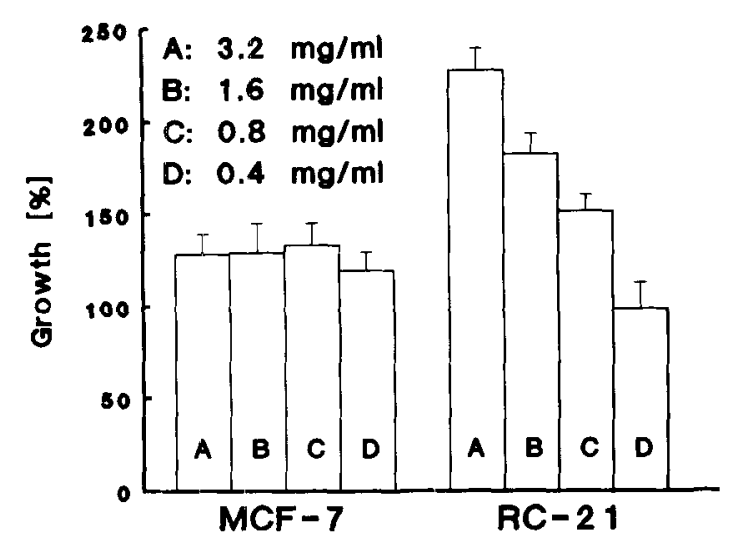

Fig. 5. Serial dilutions of concentrated $C M$ on the breast carcinoma cell line MCF-7 and the renal carcinoma cell line RC-21. Inoculum: MCF-7, 3,000; RC-21, 10,000 cells/well. Bars, SD.

been recognized as a potential site of disregulation of epithelial cell growth, which may eventually lead to neoplasia [22]. The fact that prolonged androgen administration to castrated animals does not induce the gland to grow beyond its predetermined size [2], together with the observation that withdrawal of androgens decreases epithelial cell number only in the in vivo situation where stroma is present $[8,5]$, suggests a role for stromally-derived epithelial cell growth inhibitors in the prostate.

The results presented in this paper suggest that prostatic stromal cells secrete a diffusible epithelial cell growth inhibitor(s). Anchored, as well as nonanchored, growth of the hormone-independent prostatic carcinoma cell line PC- 3 and the androgen-responsive prostatic carcinoma cell line $\mathrm{LNCaP}$ was affected. Primary epithelial cell cultures from $\mathrm{BPH}$ and prostate cancer appeared to be sensitive as well. Accumulation of antiproliferative activity in the CM was positively correlated with cell number and confined to prostate-derived stromal cells. This organspecific production appears to be a unique property, for it has not been described before in prostate research. Characterization currently underway shows that the putative factor appears to be a protein with a molecular weight $>3.5 \mathrm{Kd}$, sensitive to reducing agents, indicating the presence of S-S bridges that are needed for biological activity [23]. Several aspects concerning the production are still under investigation. For the present, serum-derived factors are required for optimal production and/or secretion. We failed to demonstrate significant effects of steroids (testosterone, dihydrotestosterone, or estradiol) in this respect, however.

That stroma not only induces a mitogenic response, but can also act as a "brake" on the epithelium, is suggested by observations made on other organ systems. Negative regulators of cell growth have been demonstrated in other fibroblast cultures [24-26]. Several coculture experiments as well as in vivo studies showed the controlling influence of the stroma on the epithelial compartment [27], ranging from induction of differentiation $[28,29]$ to tumor cell degeneration [30]. Similar experiments carried out on the male genital tract fit in with these findings. Rowley and Tindall [31] found that diffusible factors produced by fetal urogenital sinus decreased the proliferation of bladder carcinoma cells in vitro. Recently, Chung et al. [32] showed a marked growth inhibition of a hormone-independent rat prostatic tumor cell line (Nb-102-pr) when grafted in combination with urogenital sinus mesenchyme. Hayashi and Cunha [33], performing similar experiments on Dunning R3327 rat prostate tumor lines, demonstrated a reduction in epithelial cell growth rate and an apparent reduction or loss of tumorigenesis of these cells. Indeed, those findings indicate that, in the urogenital tract, mesenchymal cells are capable of inhibiting epithelial cell proliferation.

Several investigators have studied stromal-epithelial interactions in the prostate in vitro, but their reports were mainly focused on the mitogenic influence of the stroma $[34,35,19,36,21]$. Kirk et al. [37] showed an inhibition of PC-3 cell growth by lung fibroblasts, using a serum-dependent soft agar assay. So far, no reports have been published by other groups on stromally-derived epithelial cell growth inhibitors in the (adult) prostate. Remarkably, however, all studies demonstrating stromal stimulation of prostatic epithelial cell growth were performed under serum-free conditions. Regarding the lack of a growth stimulatory response of the tumor cell lines to our fibroblastconditioned medium, one might suggest that such an effect might have been masked by the relatively high serum content (5\% FCS) maximally stimulating cell proliferation. However, this is contradicted by the fact that MTT tests were performed under conditions that still allowed stimulation of growth, e.g., in the presence of higher serum concentrations.

During the past decade, much effort has been put into the development of systems for serum-free culture of prostatic cells. Indeed, a serum-free environment is ideal for testing as well as identification of regulatory peptides. However, as a consequence of this simplification, certain information may be lost, as demonstrated by the results presented in this report. These considerations bring to light a crucial dilemma in oncological research, as stated by D. Smithers: "Reduction gains precision about parts but at each step loses information about the larger organization it leaves behind" [38]. The glandular cells in the prostate receive nutrients, growth-modulating peptides, 
trophic nerve factors, and (steroid) hormones that have traversed the endothelial cells, stromal cells, extracellular matrix, and the acinar basement membrane. Consequently, the stromal compartment has ample opportunity to modify epithelial cell microenvironment. It is conceivable that (perhaps unknown) serum-derived factors may very well participate in this, for instance, by modifying stromal secretions, as was shown for androgen-induced epithelial cell proliferation in the rat prostate [7]. Thus, tests performed in the presence of serum or other undefined supplements, such as bovine pituitary extract, will provide us with useful information about physiological and pathophysiological processes, and are essential to basic oncological research. However, these supplements will eventually hamper identification and isolation of the substance(s) of interest.

So far, TGF $\beta$ is the only well-known epithelial cell growth inhibitor that has been identified in the prostate $[39,24]$. Other inhibitory peptides that have been associated with the prostate $[40,41,11]$ are not likely candidates for elaborating antiproliferative activity in our tests. The presence of TGF $\beta$ mRNA has been demonstrated in human prostatic tissue [13] as well as in rat ventral prostate [12]. In vitro studies have implicated TGF $\beta$ as a potent growth inhibitor of prostatic epithelial cells, both normal and malignant [42]. Kyprianou and Isaacs [12] showed a 40-fold increase of TGF $\beta$ mRNAs four days after castration. Androgen administration to four-day castrated rats led to a marked decrease in TGF $\beta$ mRNA, to a level comparable to its constitutive expression obtained in intact control animals, showing that expression of TGF $\beta$ is under negative androgenic regulation. In vitro and in vivo experiments showed TGF $\beta$ to induce programmed cell death of rat ventral prostate glandular cells [43]. Since these studies were performed on whole tissue homogenates, no conclusions regarding the source of TGF $\beta$ can be drawn from these tests. However, prostatic carcinoma cells have been shown to secrete TGF $\beta$ [39], while the secretion of TGF $\beta$ by fibroblasts from other organs is also well documented [24]. The work presented here shows that prostatic stroma is also capable of secreting negative mediators of epithelial cell growth. Since castration-induced cell death mainly takes place in the epithelial compartment, and the ratio of epithelial to stromal cells changes in favor of the stromal part, it is tempting to assume that the increase in TGF $\beta$ mRNA expression, an active process, takes place in the less affected cell type. Definitive answers, however, can only be expected from studies using in situ hybridization techniques with TGF $\beta$-specific probes.

From this point of view it would be very attractive to explain excessive (i.e., neoplastic) growth by a fail- ure in this system which may normally regulate prostatic size. It could, for instance, be caused by a mutation in the epithelium, rendering it insensitive to these factors [44]. This would also explain why tumors are able to metastasize without their stroma. Recently, elevated levels of TGF $\beta$ immunoreactivity have been associated with prostate cancer [45]. These observations may reflect insensitivity of cancer cells, possibly associated with a resulting failure in the negative feedback loop that controls their production and secretion by the stroma.

In summary, the data presented here demonstrate that prostatic stromal cells produce an epithelial cell growth-inhibiting activity that may share some properties with TGF $\beta$. However, especially the results regarding the organ-specific production and action appear to distinguish this putative factor from the TGF $\beta$ s, and strengthen the importance of our findings. It would be very interesting to investigate whether this factor is the major "brake" on the prostate, controlling epithelial proliferation and thus prostatic size. Further efforts will be made to unravel the identity of this prostatic stroma-derived growth inhibitor. Studies are already in progress about the relationship of this factor(s) to the type $\beta$ Transforming Growth Factors mentioned above.

\section{ACKNOWLEDGMENTS}

The authors thank the Urological Research Foundation (SUWO), Rotterdam, for its support, and our colleagues of the Department of Clinical Genetics for placing the Titertek apparatus at our disposal.

\section{REFERENCES}

1. Franks LM, Riddle PN, Carbonell AW, Gey GO: A comparative study of the ultrastructure and lack of growth capacity of adult human prostate epithelium mechanically separated from its stroma. J Pathol 100:113-119, 1970.

2. Cunha GR, Donjacour AA, Cooke PS, Mee S, Bigsby RM, Higgins SJ, Sugimura Y: The endocrinology and developmental biology of the prostate. Endocr Rev 8:338-362, 1987.

3. Chung LW, Gleave ME, Hsieh JT, Hong SJ, Zhau HE: Reciprocal mesenchymal-epithelial interaction affecting prostate tumour growth and hormonal responsiveness. Cancer Surv 11:91-121, 1991.

4. McNeal JE: Origin and evolution of benign prostatic enlargement. Invest Urol 15:340-345, 1978.

5. Isaacs JT: Antagonistic effect of androgen on prostatic cell death. Prostate 5:545-557, 1984.

6. Chung LW, Cunha GR: Stromal-epithelial interactions: II. Regulation of prostatic growth by embryonic urogenital sinus mesenchyme. Prostate 4:503-511, 1983.

7. Chang SM, Chung LW: Interaction between prostatic fibroblast and epithelial cells in culture: role of androgen. Endocrinology 125:2719-2727, 1989. 
8. McKeehan WL, Adams PS, Rosser MP: Direct mitogenic effects of insulin, epidermal growth factor, glucocorticoid, cholera toxin, unknown pituitary factors and possibly prolactin, but not androgen, on normal rat prostate epithelial cells in serum-free, primary cell culture. Cancer Res 44:1998-2010, 1984.

9. Peehl DM, Stamey TA: Serum-free growth of adult human prostatic epithelial cells. In Vitro Cell Dev Biol 22:82-90, 1986.

10. Nishi N, Matuo Y, Nakamoto T, Wada F: Proliferation of epithelial cells derived from rat dorsolateral prostate in serum-free primary cell culture and their response to androgen. In Vitro Cell Dev Biol 24:778-786, 1988.

11. Goldstein D, O'Leary M, Mitchen J, Borden EC, Wilding G: Effects of interferon $\beta$ ser and transforming growth factor $\beta$ on prostatic cell lines. J Urol 146:11731177, 1991.

12. Kyprianou N, Isaacs JT: Expression of transforming growth factor-beta in the rat ventral prostate during castration-induced programmed cell death. Mol Endocrinol 3:1515-1522, 1989.

13. Mori H, Maki M, Oishi K, Jaye M, Igarashi K, Yoshida $\mathrm{O}$, Hatanaka $\mathrm{M}$ : Increased expression of genes for basic fibroblast growth factor and transforming growth factor type $\beta 2$ in human benign hyperplasia. Prostate 16 : 71-80, 1990.

14. Kooistra A, König JJ, Romijn JC, Schröder FH: Negative control of epithelial cell proliferation by prostatic stroma. Anticancer Res 11:1495-1500, 1991.

15. Romijn JC, Verkoelen CF, Schröder FH: Application of the MTT assay to human prostate cancer cell lines in vitro: establishment of test conditions and assessment of hormone-stimulated growth and drug-induced cytostatic and cytotoxic effects. Prostate 12:99-110, 1988.

16. Dixon MA: Nomogram for ammonium sulphate solutions. Biochem J 54:457, 1953.

17. Story MT: Polypeptide modulators of prostatic growth and development. Cancer Surv 11:123-146, 1991.

18. Thompson TC: Growth factors and oncogenes in prostate cancer. Cancer Cells 2:345-354, 1990.

19. Story MT, Livingston B, Baeten L, Swartz SJ, Jacobs SC, Begun FP, Lawson RK: Cultured human prostate-derived fibroblasts produce a factor that stimulates their growth with properties indistinguishable from b-FGF. Prostate 15:355-365, 1989.

20. Gleave ME, Hsieh JT, Von Eschenbach AC, Chung LW: Prostate and bone fibroblasts induce human prostate cancer growth in vivo: implications for bidirectional tumor-stromal cell interaction in prostate carcinoma growth and metastasis. J Urol 147:1151-1159, 1992.

21. Djakiew D, Delsite R, Pflug B, Wrathall J, Lynch JH, Onoda $M$ : Regulation of growth by a nerve growth factor-like protein which modulates paracrine interactions between a neoplastic epithelial cell line and stromal cells of the human prostate. Cancer Res 51:3304-3310, 1991.

22. Van den Hooff A: Stromal involvement in malignant growth. Adv Cancer Res 50:159-196, 1988.

23. Kooistra A, Van den Eijnden-Van Raaij JM, Klaij IA, Romijn JC, Schröder FH: Stromal inhibition of prostatic epithelial cell proliferation not mediated by Transforming Growth Factor B. Submitted.

24. Barnard JA, Lyons RM, Moses HL: The cell biology of transforming growth factor beta. Biochim Biophys Acta 1032:79-87, 1990 .
25. Shirasuna K, Morioka S, Watatani K, Hayashido Y, Furusawa $H$, Sugiyama $M$, Okura $M$, Matsuya T: Growth inhibition and differentiation of human salivary adenocarcinoma cells by medium conditioned with normal human fibroblasts. Cancer Res 48:2719-2824, 1988.

26. Wu KF, Pope JH, Ellem KA: Inhibition of growth of certain human tumour cell lines by a factor derived from human fibroblast-like cell lines. I. Demonstration by mixed culture and by use of cell washings. Int J Cancer 35:477-482, 1985.

27. Kooistra A: Stromal-epithelial interactions in the prostate and its relation to steroid hormones in Berns PMJJ, Romijn JC, Schöder FH (eds): "Mechanisms of Progression to Hormone-Independent Growth of Breast and Prostatic Cancer." New Jersey, Carnforth, UK: Parthenon Publishing Group, 1991.

28. DeCosse JJ, Gossens CL, Kuzma JF: Breast cancer: induction of differentiation by embryonic tissue. Science 181:1057-1058, 1973.

29. Fong CJ, Sherwood ER, Braun EJ, Berg LA, Lee C, Kozlowski JM: Regulation of prostatic carcinoma cell proliferation and secretory activity by extracellular matrix and stromal secretions. Prostate 21:121-131, 1992.

30. Imanishi J, Hoshino S, Matsuoka $H$, Uemura H, Imanishi T, Tanaka A, Nishino H, Kishida T: Tumor degeneration by human embryonic fibroblasts and its enhancement by interferon. Cancer Res 43:4323-4326, 1983.

31. Rowley DR, Tindall DJ: Responses of NBT-II bladder carcinoma cells to conditioned medium from normal fetal urogenital sinus. Cancer Res 47:2955-2960, 1987.

32. Chung LW, Zhau HE, Ro JY: Morphologic and biochemical alterations in rat prostatic tumors induced by fetal urogenital sinus mesenchyme. Prostate 17:165$174,1990$.

33. Hayashi N, Cunha GR: Mesenchyme-induced changes in the neoplastic characteristics of the Dunning prostatic adenocarcinoma. Cancer Res 51:4924-4930, 1991.

34. Sherwood ER, Fike WE, Kozlowski JM, Lee C: Stimulation of human epithelial cell growth by stromal cell secretory products. Biol Reprod [Suppl] 38:86, 1988.

35. Kabalin JN, Peehl DM, Stamey TA: Clonal growth of human prostatic epithelial cells is stimulated by fibroblasts. Prostate 14:251-263, 1989.

36. Sherwood ER, Fong CJ, Lee C, Kozlowski JM: Basic fibroblast growth factor: a potential mediator of stromal growth in the human prostate. Endocrinology 130: 2955-2963, 1992.

37. Kirk D, Szalay MF, Kaighn ME: Modulation of growth of a human prostatic cancer cell line (PC-3) in agar culture by normal human lung fibroblasts. Cancer Res 41 : 1100-1103, 1981.

38. Smithers D: On some general concepts in oncology with special reference to Hodgkin's disease. Int J Radiat Oncol Biol Phys 9:731-738, 1983.

39. Wilding G: Response of prostate cancer cells to peptide growth factors: transforming growth factor-beta. Cancer Surv 11:147-163, 1991.

40. Limonta P, Dondi D, Moretti RM, Maggi R, Motta M: Antiproliferative effects of luteinizing hormone-releasing hormone agonists on the human prostatic cancer cell line LNCaP. J Clin Endocrinol Metab 75:207-212, 1992.

41. Mundle SD, Rao SG, Sheth NA: Antiproliferative ac- 
tion of prostatic inhibin on NRK-49F and BALB/c $3 T 3$ cell lines. Cell Biol Int Rep 16:27-35, 1992.

42. McKeehan WL, Adams PS: Heparin-binding growth factor/prostatropin attenuates inhibition of rat prostate tumor epithelial cell growth by transforming growth factor type beta. In Vitro Cell Dev Biol 24:243-246, 1988.

43. Martikainen P, Kyprianou N, Isaacs JT: Effect of transforming growth factor-beta 1 on proliferation and death of rat prostatic cells. Endocrinology 127:2963-2968, 1990.

44. Hubbs AF, Hahn FF, Thomassen DG: Increased resistance to transforming growth factor beta accompanies neoplastic progression of rat tracheal epithelial cells Carcinogenesis 10:1599-1605, 1989.

45. Thompson TC, Truong LD, Timme TL, Kadmon D, McCune BK, Flanders KC, Scardino PT, Park SH: Transforming growth factor beta 1 as a biomarker for prostate cancer. J Cell Biochem [Suppl] 16:54-61, 1992. 